\title{
Is time of birth a predictor of adverse perinatal outcome? A hospital-based cross- sectional study in a low-resource setting, Tanzania
}

Andrew Mgaya ${ }^{1,2^{*}}$, Januarius Hinju ${ }^{3}$ and Hussein Kidanto ${ }^{1,2,4}$

\begin{abstract}
Background: Inconsistent evidence of a higher risk of adverse perinatal outcomes during off-hours compared to office hours necessitated a search for clear evidence of an association between time of birth and adverse perinatal outcomes.

Methods: A cross-sectional study conducted at a tertiary referral hospital compared perinatal outcomes across three working shifts over $24 \mathrm{~h}$. A checklist and a questionnaire were used to record parturients' socio-demographic and obstetric characteristics, mode of delivery and perinatal outcomes, including 5th minute Apgar score, and early neonatal mortality. Risks of adverse outcomes included maternal age, parity, referral status and mode of delivery, and were assessed for their association with time of delivery and prevalence of fresh stillbirth as a proxy for poor perinatal outcome at a significance level of $p=0.05$.

Results: Off-hour deliveries were nearly twice as likely to occur during the night shift (odds ratio (OR), 1.62; 95\% confidence interval (Cl), 1.50-1.72), but were unlikely during the evening shift $(\mathrm{OR}, 0.58 ; 95 \% \mathrm{Cl}, 0.45-0.71)$ (all $p<0$. 001). Neonatal distress $(\mathrm{O} . \mathrm{R}, 1.48,95 \% \mathrm{Cl} ; 1.07-2.04, p=0.02)$, early neonatal deaths (OR, $1.70 ; 95 \% \mathrm{Cl}, 1.07-2.72, p=0$. $03)$ and fresh stillbirths $(\mathrm{OR}, 1.95 ; 95 \% \mathrm{Cl}, 1.31-2.90, p=0.001)$ were more significantly associated with deliveries occurring during night shifts compared to evening and morning shifts. However, fresh stillbirths occurring during the night shift were independently associated with antenatal admission from clinics or wards, referral from another hospital, and abnormal breech delivery (OR 1.9; $95 \% \mathrm{Cl}, 1.3-2.9, p=0.001$, for fresh stillbirths; OR, 5.0; 95\% Cl 1.7-8.3, $p<0.001$, for antenatal admission; OR, 95\% Cl, 1.1-2.9, $p<0.001$, for referral form another hospital; and OR 1.6; $95 \% \mathrm{Cl}$ $1.02-2.6, p=0.004$, for abnormal breech deliveries).

Conclusion: Off-hours deliveries, particularly during the night shift, were significantly associated with higher proportions of adverse perinatal outcomes, including low Apgar score, early neonatal death and fresh stillbirth, compared to morning and evening shifts. Labour room admissions from antenatal wards, referrals from another hospital and abnormal breech delivery were independent risk factors for poor perinatal outcome, particularly fresh stillbirths.
\end{abstract}

Keywords: Perinatal outcome, Time of birth, Quality of care, Low-resource setting

\footnotetext{
* Correspondence: andrew.mgaya@kbh.uu.se

'Department of Obstetrics and Gynaecology, Muhimbili National Hospital,

P.O. Box 65000, Dar es Salaam, Tanzania

2Department of Women's and Children's Health, International Maternal and

Child Health, Academic Hospital, Uppsala, Sweden

Full list of author information is available at the end of the article
} 


\section{Background}

Improvement of the quality of obstetric and neonatal care is regarded as a prerequisite for preventing maternal and perinatal mortality [1], especially in the postmillennium development goal era [2]. In low-resource settings, substandard care accounts for significant numbers of maternal [3] and neonatal deaths [4], of which one-third include intrapartum stillbirth [5]. In Tanzania, substandard care contributes to $6 \%$ of labour-related maternal deaths [6] and $30 \%$ of perinatal mortality due to intrapartum asphyxia of mostly term deliveries [7]. Numerous studies have suggested that there is a higher risk of adverse perinatal outcome during off-hours deliveries, i.e., during evening and night shifts, or at weekends [8-15], compared to morning and afternoon office hours. These adverse outcomes include fetal injury [9, $11]$, perinatal mortality $[8,10]$ and early neonatal death (ENND) $[12,13]$. Other studies associated intrapartum fetal death [13], and admission to neonatal intensive care unit (NICU) [9], with births occurring during weekends. Conversely, other authors did not find any difference in the risk of poor perinatal outcome during off-hours [1618]. This evidence of high risk of adverse outcomes during off-hours has led to a general questioning of the quality of care and availability of access to skilled care providers, organization of work and availability of equipment, and supplies during off-hours.

One study, reporting on the circadian rhythm of the perinatal mortality rate throughout the week, found that the strongest determinants of the rate were associated with the selection of time of delivery of low birth weight fetuses in the afternoon hours based on obstetric risks, availability of obstetric and neonatal care, and chronobiologic behaviour [19]. Another author associated increased adverse perinatal outcomes with increased rate of low umbilical artery $\mathrm{pH}$ in caesarean section (CS) during night shifts [20]. However, umbilical blood gas analysis has also been found to be unreliable as a neonatal assessment tool for infants with an Apgar score of less than 7; and especially in high-risk pregnancies, including those delivered by CS, pre-term pregnancies and twin pregnancies [21].

Stress and severe fatigue in care professionals that is related to long working hours compromises patients' safety [22-24]; however, the link between hours of work and patient safety is still unclear due to a lack of consistent reports of an association of sleep deprivation with medical error [25, 26], and patient safety [27]. Nonetheless, restricted on-call duty (50-80 working hours per week) has been reported to alleviate acute stress, fatigue, and loss of sleep $[28,29]$; and also has a positive impact on the quality of life of health care providers [30], and, subsequently, can improve quality of care [2]. Coincidental observations through attending hospital management and departmental meetings at Muhimbili National Hospital (MNH) highlighted low patient-tocaregiver ratio, periodic unanticipated high rates of deliveries, and limited supplies during night and evening shifts compared to morning shifts. Despite these discussions, no scientific evidence has been sought to confirm how the discrepancy between the demand and supply of obstetric care affects pregnancy outcomes.

Few researchers in developing countries [31], and none we know of in Tanzania, have addressed the relationship between time of delivery and perinatal outcome. Lack of clear evidence of whether quality of care differs between time of delivery in relation to the structure and process of care compromises the overall effectiveness and efficiency of obstetric and neonatal interventions. Understanding the contributing factors for perinatal morbidities and mortalities is the key to reducing the number of adverse perinatal outcomes. Therefore, this study intended to answer the following research question: Is time of birth a predictor of adverse perinatal outcome? We estimated and compared the prevalence of adverse perinatal outcome across the three hospital working shifts, including the morning shift (7 am$2 \mathrm{pm})$, evening shift $(2 \mathrm{pm}-8 \mathrm{pm})$, and night shift (8 pm-7 am).

\section{Methods}

\section{Study design and settings}

We conducted a cross-sectional study at MNH in 2012. $\mathrm{MNH}$ is the highest referral hospital in Tanzania, and is a teaching hospital for Muhimbili University of Health and Allied Sciences (MUHAS). The hospital is situated in Dar es Salaam, which, according to the Tanzania Demographic Health Survey (TDHS 2010), has a population of about 4.5 million and an annual population growth rate of $4.3 \%$. As one of the four consultant hospitals in Tanzania, MNH serves as a referral centre for the city of Dar es Salaam and the neighbouring coastal region. The annual number of deliveries in the hospital in 2012 was between about 8000 and 9000, of which $70 \%$ were self-referrals and hence the majority were also lowrisk deliveries. Furthermore, out of 15 to 40 daily deliveries, 30 to $60 \%$ delivered by CS [32]. The peak delivery period was March to April and the lowest delivery period was December to January. According to the birth registry, during 2012-2015, the MMR of women who delivered at MNH increased from 96 to 146/100,000 live births, and the fresh stillbirth ratio and early neonatal deaths decreased from $32 / 1000$ to $26 / 1000$ and from 27/ 1000 to $16 / 1000$, respectively.

The obstetric wards were attended by 35 obstetricians, 25 obstetrics and gynecology residents, 2 registrars and 25 nurse midwives. Daily routines included a daily grand ward round for 24-h call reports, and major ward rounds 
in the labour room, obstetric ICU and admitting antenatal/postnatal ward. The outpatients' clinic and elective obstetrics and gynecological surgeries were included among daily hospital routines. Doctors on call work for $24 \mathrm{~h}$ in a team comprised of one intern doctor, two residents (one in the labour ward and another in the obstetric theater), and one specialist and one consultant obstetrician who were mostly called for a second opinion or in case of emergency. The length of working hours for nurses was $8 \mathrm{~h}$ on the morning, $6 \mathrm{~h}$ on the evening and $11 \mathrm{~h}$ on the night shift. The nurse-parturient ratio averaged at 1:3-5 on the morning and evening shifts, but $1: 6-8$ on the night shifts. After a normal vaginal delivery, the mothers and babies were observed in hospital for 6-10 h. During this time, babies are vaccinated with BCG and polio vaccinations before being discharged. Babies delivered by CS or those who were sick were admitted to the neonatal ward, which also admits sick babies from other lower referral hospitals.

\section{Study population and sampling}

All parturients who delivered at MNH during the study period were identified from the midwifery registry and assessed for eligibility for recruitment. The exclusion criteria included patients that had a high risk of, or preexisting conditions that could lead to, poor maternal and/ or perinatal outcomes: history of peripartum complication such as abruption placenta, placenta previa and eclampsia; and neonatal complications, including congenital anomalies and intrauterine fetal deaths confirmed antenatally by ultrasound or macerated stillbirths. All parturients who delivered $<28$ weeks of gestation, those who delivered twins, and those delivered by elective CS were also excluded.

\section{Data collection}

Data were collected for 5 months (June to December) from the partogram and case notes using a checklist and questionnaire. The variables of interest included: sociodemographic characteristics, such as age, marital status and level of education; obstetric characteristics, including parity, gestation age, source of admission, number of gestations, nature of labour and mode of delivery; and perinatal outcomes, including 5th minute Apgar scores, birth trauma, intrapartum stillbirth and early neonatal death. The data were collected by one of the researchers from the midwifery registry, however, in case of incomplete or ambiguous information from the registry, mothers were interviewed for clarification. Neonates who were admitted to the neonatal unit were followed up for seven days to document the early neonatal outcome. Alternatively, neonates who were not admitted after delivery were considered to have good outcomes, hence they were not followed up. Verification of the information recorded by questionnaire and checklist was completed daily, and hence, no case was excluded from the analysis.

\section{Definition of terms}

Adverse perinatal outcomes were defined as; Apgar score $<7$ at $5 \mathrm{~min}$, fresh stillbirth, early neonatal death, and physical birth trauma (including skull fracture, clavicle fracture, facial nerve palsy and brachial plexus injuries). The perinatal period commenced from 28 completed weeks of gestation or when the neonatal birth weight was above $500 \mathrm{~g}$.

Early neonatal death was defined as death of a newborn within 7 days post-delivery. A stillbirth was defined as the delivery of a dead newborn within the perinatal period, and fresh stillbirth was the birth of a dead fetus without postmortem changes based on physical appearance, including blistered or peeled-off skin. A perinatal death was a neonatal death during the perinatal period and hence included stillbirths and early neonatal deaths. Primipara referred to a woman experiencing her first delivery, while Multipara was defined as a woman having her second or more delivery. A work shift meant a period of working hours within a 24-h cycle that was divided into a morning shift from 7 am to $2 \mathrm{pm}(8 \mathrm{~h})$, an evening shift from $2 \mathrm{pm}$ to $7 \mathrm{pm}(6 \mathrm{~h})$, and a night shift from $7 \mathrm{pm}$ to 7 am $(12 \mathrm{~h})$.

\section{Data analysis}

Data entry and cleaning was performed using Epi Info ${ }^{\text {Tw }}$ version 6, and then data were transferred to SPSS version 21.0 (SPSS, Armonk, NY: IBM Corporation) for statistical analyses. Data cleaning included removing typographic errors and duplicated information and amending incomplete or incongruent information using case notes and ward report logs and by interviewing the mother. Statistically significant differences in associations between maternal characteristics, mode of delivery and perinatal outcome to time of birth were assessed using chi-squared $\chi^{2}$ test for categorical variables, while Student's $t$-test was used to assess continuous variables at a significance level of $p=0.05$. Multiple logistic regression analysis was used to measure independent associations between selected predictors of adverse outcomes in relation to night shifts.

\section{Results}

During the study period, 3193 women delivered, out of which 557 women were excluded. Excluded participants were 327 who delivered by elective CS, and 9 with multiple gestations, of which 7 were twins and 2 were triplets. Other excluded women were 49 who had abruption placentas, and 99 who delivered before 28 weeks of gestation. One mother who had anencephalic fetus, 51 who 
had macerated stillbirths, and 22 with antenatal sonographic diagnosis of intra-uterine fetal deaths (IUFD), were also excluded. Therefore, the remaining 2636 deliveries were analysed (Table 1). Most of the deliveries occurred during the night shift (49\%), and the evening shift had the least number of deliveries (21\%). Thus, offhours deliveries were nearly twice as likely to occur during the night shift (OR, 1.62; 95\% CI, 1.50-1.72, $p<0.001$ ) but were less likely during the evening shift (OR, 0.58; 95\% CI, 0.45-0.71, $p<0.001$ ).

When comparing obstetric characteristics to timing of delivery (Table 2), the majority of deliveries were parturients aged between 20 and 35 years $(80 \%)$, with a primary school education (60\%) and were multiparas (65\%). Furthermore, almost all deliveries were full-term delivery (92\%). Most teenagers delivered during the morning shift (7.2\%) compared to the evening (3.9\%) and night shifts (2.3\%). Parturients aged 35 years and above were nearly evenly distributed during the morning shift (14.1\%) compared to the evening (13.5\%) and night shifts (13.8\%). Nearly the whole studied group had some level of formal education, i.e., at least primary education level, with the majority being multiparas and evenly distributed across the morning (63.5\%), evening (68.3\%) and night shifts (64.2\%). Two-thirds of the deliveries came direct to the hospital from home, and nearly all of the remainder were referred from other hospitals. Referrals from other hospitals mostly delivered during the night shift (38.2\%) compared to evening (33.3\%) and morning shifts $(29.9 \%)$. On the other hand, parturients arriving from home mostly delivered during the morning shift $(68.7 \%)$ compared to those who delivered in the evening (65\%) and night shifts (60.8\%).

When comparing the distribution of mode of deliveries (Table 3), half of the studied group delivered vaginally, and the majority of the remaining half by cesarean section (46\%). Equal distribution of the remaining $4 \%$ of participants had abnormal breech delivery or were delivered by low cavity vacuum extraction (LCVE). No statistically significant difference was found in the rate of vaginal deliveries across the three shifts, i.e., the morning (52\%), evening (52\%) and night shifts (48\%). Similarly, CS deliveries were evenly distributed during the morning $(46 \%)$, evening $(47 \%)$ and night shifts $(48 \%)(p=0.07)$. However, most abnormal breech deliveries (1.6\%)

Table 1 Percentage distribution of deliveries in three shifts within $24 \mathrm{~h}$

\begin{tabular}{llll}
\hline Time of delivery & $\begin{array}{l}\text { No. of deliveries } \\
N=2636(\%)\end{array}$ & OR $(95 \% \mathrm{Cl})$ & $P$-value \\
\hline Morning shift & $780(30.0 \%)$ & 1 & \\
Evening shift & $577(21.0 \%)$ & $0.58(0.45-0.71)$ & $<0.001$ \\
Night shift & $1279(49.0 \%)$ & $1.62(1.50-1.72)$ & $<0.001$ \\
\hline
\end{tabular}

occurred during the night shift compared to morning $(1 \%)$ and evening shifts $(0.5 \%)(p=0.02)$. A similar pattern was observed for the LCVE deliveries, most of which $(2.3 \%)$ were performed at night compared to the morning (1.8\%) and evening (0.9\%) shifts, $(p=0.03)$

Poor perinatal outcome was associated with $10 \%$ of neonatal distress (Apgar score $<7$ at 5 th $\mathrm{min}$ ); $4 \%$ of early neonatal deaths and $6 \%$ of fresh stillbirths (Table 4). Night shift deliveries had twice the odds of poor perinatal outcome compared to morning shift deliveries (OR 1.48, 95\% CI; $1.07-2.04, p=0.02$, for neonatal distress; OR, $1.70 ; 95 \% \mathrm{CI}, 1.07-2.72, p=0.03$, for ENND; and OR, 1.95; 95\% CI, $1.31-2.90, p=0.001$, for FSB). No significant difference was found in the odds of poor perinatal outcome in the evening shift compared to the morning shift deliveries. Using multiple logistic regression analysis (Table 5), night shifts were independently associated with fresh stillbirths, antenatal admission from clinic or antenatal wards, referral from another hospital, and abnormal breech delivery (OR 1.9; 95\% CI, $1.3-2.9 ; p=0.001$, for FSB; OR 5.0; 95\% CI 1.7-8.3; $p<0.001$, for antenatal admission; OR 1.2; 95\% CI, $1.1-$ 2.9; $p<0.001$, for referral from another hospital; and OR 1.6: $95 \%$ CI 1.02-2.6; $p=0.004$, for abnormal breech delivery(ABD)).

\section{Discussion \\ Main findings}

The night shift was significantly associated with adverse perinatal outcomes, including low Apgar score, early neonatal death, and fresh stillbirth when compared with the morning and evening shifts. Our findings were consistent with some previous findings $[10,12,13]$; although refuted by others $[17,18]$ from settings with access to standardized care. The Dar es Salaam public hospitals birth registries, including that of $\mathrm{MNH}$, confirmed that most of the daily deliveries occurred during the night shift compared to the morning and evening shifts. [3235]. The most common groups of patients who were admitted to the delivery room during the night shift included patients from antenatal wards, referrals from other hospitals, and a significant number were abnormal breech deliveries. These groups of patients presumably possessed an independent risk of fresh stillbirth that was associated with maternal and fetal characteristics or obstetric risk factors that either led to their admission from the antenatal care or caused by delays in care as they travelled through the referral system. Therefore, the demonstrated risk of poor perinatal outcomes during off-hours in this study could have been associated with timing of delivery rather than the quality of care provided during off-hours. Alternatively, the exclusion of parturients with a known history of pregnancy complications to eliminate the confounding effect of antenatal 
Table 2 Demographic and obstetric characteristics of according to time of birth

\begin{tabular}{|c|c|c|c|}
\hline \multirow{2}{*}{$\begin{array}{l}\text { Socio-demographic } \\
\text { characteristics }\end{array}$} & \multicolumn{3}{|c|}{ Time of delivery (Shifts) } \\
\hline & Morning $n=780(\%)$ & Evening $n=577(\%)$ & Night $n=1279(\%)$ \\
\hline \multicolumn{4}{|l|}{ Age } \\
\hline$<20$ yrs & $56(7.2)$ & $23(3.9)$ & $29(2.3)$ \\
\hline $20-35$ yrs & $614(78.8)$ & $476(82.5)$ & $1012(83.8)$ \\
\hline $35+y r s$ & $110(14.1)$ & $78(13.5)$ & $176(13.8)$ \\
\hline \multicolumn{4}{|l|}{ Education level } \\
\hline No formal education & $10(1.3)$ & $13(2.2)$ & $19(1.5)$ \\
\hline Primary School & $443(56.8)$ & $338(58.6)$ & $792(62.0)$ \\
\hline Secondary School & $216(27.7)$ & $146(25.3)$ & $305(23.8)$ \\
\hline College education & $111(14.2)$ & $80(13.9)$ & $163(12.7)$ \\
\hline \multicolumn{4}{|l|}{ Parity } \\
\hline Primipara & $276(35.4)$ & $192(33.3)$ & $458(35.8)$ \\
\hline Multipara & $504(64.6)$ & $385(66.7)$ & $821(64.2)$ \\
\hline \multicolumn{4}{|l|}{ Gestation age } \\
\hline 36 weeks & $76(9.7)$ & $48(8.3)$ & $106(8.3)$ \\
\hline $37+$ weeks & $704(90.3)$ & $529(91.7)$ & $1173(91.7)$ \\
\hline \multicolumn{4}{|l|}{ Source of admission } \\
\hline Referral another Hospital & $233(29.9)$ & $192(33.3)$ & $489(38.2)$ \\
\hline From home & $536(68.7)$ & $375(65.0)$ & $777(60.8)$ \\
\hline Antenatal admissions & $11(1.4)$ & $109(1.7)$ & $6(1.0)$ \\
\hline
\end{tabular}

complication might have reduced the resulting proportions of adverse perinatal outcome, either among antenatal admissions or referred patients.

In our study, teenagers were not associated with adverse perinatal outcomes and the majority delivered in the morning shift. However, teenage pregnancy has been found to have higher perinatal risks, including anaemia [36], placental problems [37], preterm delivery [36-38] and low birth weight [15]. Nevertheless, although not part of this study, teenagers require special attention due to the abovementioned risks and others, including adherence to antenatal care and late booking [39], substance abuse [40], and possibly financial instability and dependence compared to adult and/or married pregnant women $[41,42]$. The characteristics of our study participants included a majority of multiparas who delivered at term, and from whom one- third had secondary or college education, hence a protective effect on the exposure to obstetric risks.

Consistent with previous studies [42, 43], high CS rate was associated with very low use of LCVE, contrary to the WHO recommendation of appropriate use of emergency obstetric and newborn care (EmONC) services. Further, despite evidence of CS being associated with maternal near miss and death [44], CS was not independently associated with an increased risk of perinatal outcome, and was evenly distributed across the daily shifts. The LCVE rate was less than $2 \%$, consistent with previous studies [42, 43]; and, therefore, in a way confirmed the tendency of obstetricians to avoid difficult obstetric procedures [44]. On the other hand, the low LCVE rate implied an opportunity to improve EmONC.

Table 3 Percentage distribution of mode of delivery in three shifts within $24 \mathrm{~h}$

\begin{tabular}{lllll}
\hline $\begin{array}{l}\text { Mode } \\
\text { of } \\
\text { delivery }\end{array}$ & \multicolumn{2}{l}{ Time of delivery (Shifts) } & Night $n=1279(\%)$ & $P$-value \\
\cline { 2 - 4 } SVD & Morning $n=780(\%)$ & $300(52.0)$ & $623(48.6)$ & $606(47.5)$ \\
C/S & $397(51.0)$ & $269(46.6)$ & $21(1.6)$ & 0.1 \\
ABD & $361(46.2)$ & $3(0.5)$ & $29(2.3)$ & 0.02 \\
LCVE & $8(1.0)$ & $5(0.9)$ & & 0.03 \\
\hline
\end{tabular}


Table 4 Perinatal outcome of current delivery according to three shifts of $24 \mathrm{~h}$

\begin{tabular}{|c|c|c|c|c|c|c|c|c|}
\hline \multirow[t]{3}{*}{ Perinatal outcome } & \multicolumn{8}{|c|}{ Time of delivery (Shifts) } \\
\hline & \multicolumn{2}{|l|}{ Morning } & \multicolumn{3}{|l|}{ Evening } & \multicolumn{3}{|l|}{ Night } \\
\hline & $N=780(\%)$ & OR $(95 \% \mathrm{Cl})$ & $N=577(\%)$ & OR(95\%Cl) & $P$-Value & $N=1279(\%)$ & OR(95\%Cl) & $P$-value \\
\hline Apgar Score $<7$ at $5^{\text {th }}$ min & $57(7.3)$ & 1 & $44(7.6)$ & $1.05(0.09-1.58)$ & 0.83 & $134(10.4)$ & $1.48(1.07-2.04)$ & 0.02 \\
\hline END & $25(3.2)$ & 1 & $18(3.1)$ & $0.97(0.53-1.79)$ & 0.93 & $69(5.3)$ & $1.70(1.07-2.72)$ & 0.03 \\
\hline FSB & $35(4.4)$ & 1 & $29(5.01)$ & $1.16(0.69-1.93)$ & 0.65 & $105(8.2 \%)$ & $1.95(1.31-2.90)$ & 0.001 \\
\hline
\end{tabular}

\section{Interpretation of the results}

Increased prevalence of perinatal morbidity and mortality during off-hours could generally be associated with pre-existing problems in low-resource settings, including delays in reaching and receiving care among referral cases $[45,46]$. A high proportion of referred patients in labour during the night hours might have overwhelmed the available resources allocated to the perhaps underestimated number of anticipated night deliveries. This underestimation could either be due to the failure of hospital management to appreciate the daily trend of deliveries or in an attempt to evenly distribute the limited resources; which, in this case, was counterproductive.

The majority of antenatal ward admissions who gave birth during the night shift were presumably pregnant women with poor medical and obstetric histories, as an indication for admission, and hence, they experienced an added recurrent risk of poor perinatal outcome compared to other admissions. On the other hand, some of the admissions might have included low-risk selfreferrals, as $\mathrm{MNH}$ also received some private patients, although the majority of these came from home. As previously demonstrated [47-50], referrals from other hospitals experienced first-, second- or even third-levels of delay in receiving care at the referring point. The transfer process through the primary and secondary referral facilities could be commonly occurring in the morning and afternoon before the pregnant women eventually

Table $\mathbf{5}$ Logistic regression of predictors of adverse outcome associated with the night shift

\begin{tabular}{lll}
\hline Variable & OR $(95 \% \mathrm{Cl})$ & $P$-value \\
\hline Fresh still birth & $1.9(1.3-2.9)$ & 0.001 \\
Maternal Age & & \\
$\quad<20$ yrs & $1.0(0.9-2.9)$ & 0.98 \\
$\quad>35$ yrs & $1.0(0.9-2.8)$ & 0.76 \\
Primiparity & $1.0(0.9-1.9)$ & 0.87 \\
Antenatal admission & $5.0(1.7-8.3)$ & $<0.001$ \\
Referrals from another Hospital & $1.2(1.1-2.9)$ & $<0.001$ \\
Mode of delivery & & \\
$\quad$ SVD & $1.0(0.9-2.7)$ & 0.1 \\
LCVE & $1.3(0.9-3.3)$ & 0.21 \\
ABD & $1.6(1.02-2.6)$ & 0.04 \\
\hline
\end{tabular}

reach $\mathrm{MNH}$ during the night shift. One can reasonably argue that an increased prevalence of poor perinatal outcome at the highest referral point should be anticipated during the night shift rather than the morning or evening shifts.

The review of the birth registry [32] demonstrated that not all reasons for referral to $\mathrm{MNH}$ were due to obstetric complications. The majority of referral indications were non-obstetric, including a lack of sutures, a nonfunctional theater bed or anaesthetic machine, consumables being out of stock, among others [51, 52]. This highlights that an overwhelmingly increasing workload of deliveries is placed at the highest referral point, without a corresponding increase of resources. The relatively compromised quality of care in terms of human and physical resources during the night compared to the daytime could place increased demand of resources and intensity of work, and hence elevate the level of poor outcomes during off-hours. For example, on-call doctors commence work at 8 am and receive 15 to 40 deliveries per day, among which $30 \%$ to $60 \%$ are CS, which can reasonably cause severe exhaustion to the care providers in the night shift; and therefore, reduce the quality of the process and outcome of care $[53,25]$.

We found high rates of CS, which agreed with a previous report [43], which addresses an increasing rate of CS in low-risk groups, and exposed questionable CS indications based on the absence of concomitantly improved neonatal outcomes. Despite a lack of association between CS and poor perinatal outcome in our study, assigning unnecessary CS interventions in resourcelimited settings, such as those in Tanzania, indirectly deprives others who are in need of the intervention; hence adding to the risk of poor perinatal outcome. Importantly, a maternal near-miss study on CS at Dar es Salaam public hospitals found CS to be associated with life-threatening events [54], and other studies found delays in the timeline for intervention after taking the decision to perform CS $[51,52]$, the result of which is that the negative effect might be higher during the night shift when there were more deliveries than during morning or evening shifts, which have less deliveries [32].

Supported by another author [12], our study setting has unlimited access to senior doctors and midwives during the morning shifts compared to off-hours shifts. 
The benefits of the presence of senior staff during the morning shifts include better workforce and clinical and organizational decision making compared to other shifts, when seniors may be off work. However, the benefits of professional seniority might not necessarily mean better skills in obstetrics and midwifery. Nevertheless, the positive impact of the presence of senior professionals depends on the adequacy of resources and the participation of senior doctors in the daily routine. During this study, senior and experienced nurse midwives were mostly administrators and hence performed less clinical work. Similarly, senior doctors were usually available during the grand rounds, past the 24-h admission report and occasionally during the service morning ward rounds. Senior doctors who were on call attended emergency cases, when called to do so during their 24-h on-call duty. Similar to previous findings [25], the absence of senior doctors during off-hours compromised decision making, hence causing delays or precipitating suboptimal interventions that could have led to poor delivery outcomes. The strengthening of leadership skills during working hours and the off-hours shift, as well as the teamwork skills during the on-call emergency shift, has been found to improve practice [51, 52]. The presence of senior staff and the proportion of working staff per shift positively influences perinatal outcome with some variation from hospital to hospital [53, 25].

High prevalence of perinatal outcome (i.e., 89/1000 deliveries for Neonatal distress, 42/1000 for ENND, and $64 / 1000$ for fresh stillbirth), in a relatively low-risk group of parturients in our study, highlights the overall deficiencies in EmONC [55]. However, the observed independent association of adverse perinatal outcome such as fresh stillbirths with referrals from other hospitals, antenatal admissions and ABD during the night shift stressed a need for special considerations for 24/7 standardization of EmONC within the existing health care system [17].

\section{Study limitations}

Our study had the advantage of having a large sample size, hence it yielded high power. However, as a crosssectional design we failed to make causal inferences in the highlighted predictors of poor perinatal outcome. A possible bias included an overlapping time of case management from one shift to another, which might have over-expressed adverse perinatal outcome in a particular shift. Caution should be taken in the generalization of hospital-based findings to the general population due to discrepancies in the proportions of the number and mode of deliveries, and in the availability of equipment, supplies and skilled human resources. Importantly, because of the low prevalence of some variables, such as
LCVE and ABD, a bias in the comparability of events could be present.

\section{Conclusion}

Off-hours deliveries, particularly during the night shift, were significantly associated with higher proportions of adverse perinatal outcomes, including low Apgar score, early neonatal death and fresh stillbirth, compared to morning and evening shifts. Labour room admissions from antenatal wards, referrals from another hospital and abnormal breech delivery were independent risk factors for poor perinatal outcome, particularly fresh stillbirths. However, absence of poor outcomes based on the time of delivery should be interpreted with caution, as stillbirths may simply be associated with the timing of delivery as opposed to the time of the occurrence of the event. From these findings, we recommend that:

1. The most urgent and cost-effective ways to reduce maternal and perinatal adverse outcome should include upgrading and improving the quality of EmONC services within the existing health care systems, especially in lower referral points, so as to reduce the number of referrals from the national referral hospitals.

2. The hospital administration should appropriately allocate drugs, equipment and supplies according to demand per shift; and re-structure duty rosters to allow for a higher number of staff during off-hours, and the presence of senior and more experienced staff during all 24-h shifts. Working hours for doctors on call should be reduced and perhaps become 12-h on-call shifts instead of 24-h on-call. The restricted working hours will not only reduce staff fatigue but will also motivate them to accept extra workload when necessary, hence improving quality of care.

3. $\mathrm{MNH}$ and lower referring hospital should introduce an internal quality assurance system through routine audits, with the purpose of continuously assessing and improving the quality and safety of obstetric interventions including the use of partogram, LCVE and CS.

\section{Abbreviations}

ABD: Abnormal breech delivery; CS: Caesarean section; EmONC: Emergency Obstetric and Neonatal Care; ENND: Early neonatal deaths; IUFD: Intra-uterine fetal death; LCVE: Low cavity vacuum extraction; MMR: Maternal Mortality Ratio; MNH: Muhimbili National Hospital; TDHS: Tanzania Demographic Health Survey; WHO: World Health Organization

\section{Acknowledgements}

The authors thank all mothers who agreed to participate in the study. The contribution of the obstetricians and nurses in the Department of Obstetrics and Gynaecology at MUHAS and MNH is highly appreciated. 


\section{Funding}

The authors declare and appreciate the financial contribution from the Ministry of Health of Tanzania.

\section{Availability of data and materials}

The data generated and analyzed are not publicly available due to ethical and regulatory reasons in accordance with $\mathrm{MNH}$ research data sharing/ transfer policy. The MNH Research Ethics Review Board shall release specified data upon request through the hospital research unit, e-mail: elective.students@mnh.or.tz

\section{Authors' contributions}

AM participated in the development of the study, analysed and interpreted data, and developed and wrote the first manuscript and final manuscript. JH conceived the study and carried out data collection and analysis. HK conceived the study, participated in data analysis, and development of the first and final versions of the manuscript. All authors have read and accepted the submission of the final manuscript.

\section{Competing interests}

The authors declare that they have no competing interests.

\section{Consent for publication}

Not applicable

\section{Ethics approval and consent to participate}

Study procedures followed the approved ethical guidelines for biomedical research involving human subjects (including human material or human data) in compliance with the Helsinki Declaration (https://www.wma.net/ policies-post/wma-declaration-of-helsinki-ethical-principles-for-medicalresearch-involvinghuman-subjects/). All reviewed case notes were coded and anonymized. Confidentiality was guaranteed by restricting access to the data to researchers and occasionally conducting interviews in private. Ethical clearance for the study procedures was granted by the MUHAS-Research ethics and publication committee (Ref. no. MU/DPG/AEC/MUHAS/120501) and permission to conduct the study was granted by the Executive Director of $\mathrm{MNH}$. Patients whose case notes had missing data and require an interview to fill in the missing information, a procedure for a signed written consent for voluntary participation was in place.

\section{Publisher's Note}

Springer Nature remains neutral with regard to jurisdictional claims in published maps and institutional affiliations.

\section{Author details}

'Department of Obstetrics and Gynaecology, Muhimbili National Hospital, P.O. Box 65000, Dar es Salaam, Tanzania. ²Department of Women's and Children's Health, International Maternal and Child Health, Academic Hospital, Uppsala, Sweden. ${ }^{3}$ Department of Obstetrics and Gynaecology, Benjamin Mkapa referral Hospital, Dodoma, Tanzania. ${ }^{4}$ Department of Obstetrics and Gynaecology, Muhimbili University of Health and Allied Sciences, Dar es Salaam, Tanzania.

\section{Received: 8 July 2015 Accepted: 26 May 2017}

\section{Published online: 12 June 2017}

\section{References}

1. Graham W, Wagaarachchi P, Penney G, McCaw-Binns A, Antwi KY, Hall MH. Criteria for clinical audit of the quality of hospital-based obstetric care in developing countries. Bull World Health Organ. 2000;78(5):614-20.

2. WHO. Standards for improving maternal and new-born health in health facility. Geneva: WHO; 2016

3. Hogan MC, Foreman KJ, Naghavi M, Ahn SY, Wang M, Makela SM, et al. Maternal mortality for 181 countries, 1980-2008: a systematic analysis of progress towards millennium development goal 5. Lancet. 2010;375(9726): 1609-23.

4. Rajaratnam JK, Marcus JR, Flaxman AD, Wang $H$, Levin-Rector A, Dwyer $L$, et al. Neonatal, post neonatal, childhood, and under-5 mortality for 187 countries, 1970-2010: a systematic analysis of progress towards millennium development goal 4. Lancet. 2010;375(9730):1988-2008.
5. Lawn JE, Blencowe H, Pattinson R, Cousens S, Kumar R, Ibiebele I, et al. Stillbirths: where? When? Why? How to make the data count? Lancet. 2011; 377(9775):1448-63.

6. Sorensen BL, Elsass P, Nielsen BB, Massawe S, Nyakina J, Rasch V. Substandard emergency obstetric care - a confidential enquiry into maternal deaths at a regional hospital in Tanzania. Tropical med Int Health. 2010;15:894-900.

7. Schmiegelow C, Minja D, Oesterholt M, Pehrson C, Suhrs HE, Bergstr m S, et al. Factors associated with and causes of perinatal mortality in northeastern Tanzania. Acta Obstet Gynecol Scand. 2012;91(9):1061-8.

8. Gijsen R, Hukkelhoven C, Schipper M, Ogbu U, de Bruin-Kooistra M, Westert G. Effects of hospital delivery during off-hours on perinatal outcome in several subgroups: a retrospective cohort study. BMC Pregnancy Childbirth. 2012;12:92.

9. de Graaf JP, Ravelli AC, Visser GH, Hukkelhoven C, Tong WH, Bonsel GJ, et al. Increased adverse perinatal outcome of hospital delivery at night. BJOG. 2010;117(9):1098-107.

10. Geburtshilfe Z. Why are babies born at night at increased risk of early neonatal mortality? Neonatal. 2003;207(4):137-42.

11. Urato AC, Craigo SD, Chelmow D, O'Brien WF. The association between time of birth and fetal injury resulting in death. Am J Obstet Gynecol. 2006;195:1521-6.

12. Bendavid E, Kaganova Y, Needleman J, Gruenberg L, Weissman JS. Complication rates on weekends and weekdays in US hospitals. Is J med. 2007;120:422-8.

13. Stephansson O, Dickman PW, Johansson AL, Kieler H, Cnattingius S. Time of birth and risk of intrapartum and early neonatal death. Epidemiology. 2003; 14:218-22.

14. Paccaud F, Martin-Beran B, Gutzwller F. Hour of birth as a prognostic factor for perinatal death. Lancet. 1988:1:340-3.

15. Heller G, Misselwitz B, Schmidt S. Early neonatal mortality, asphyxia related deaths, and timing of low risk births in Hesse, Germany, 1990-8: observational study. Br med J. 2000;321:274-5

16. Caughey AB, Urato AC, Lee K-A, Thiet M-P, Washington EW, Laros RK Jr. Time of delivery and neonatal morbidity and mortality. AJOG 2008; 496.e1-496.e5.

17. Tavares S, Cavaco-Gomes J, Moucho M, Severo M, Mateus M, Ramalho C, et al. 24/7 presence of medical staff in the labor Ward; no day-night differences in Perinatal and maternal outcomes. Am J Perinatol. 2016; doi: 10.1055/s-0036-1593809.

18. Butler K, Ramphul M, Dunney C, Farren M, McSweeney A, McNamara K, et al. A prospective cohort study of the morbidity associated with operative vaginal deliveries performed by day and at night. BMJ Open. 2014;4(10):e006291.

19. Ruffieux C, Marrazi A, Paccaud F. The circadian rhythm of the perinatal mortality rate in Switzerland. Am J Epidemiol. 1992;135:936-92.

20. Suzuki S, Nakai M, Hiraizumi $Y$, Satomi M. Time of delivery and Perinatal outcome. J Nippon Med Sch. 2010;77:277-81.

21. van Tetering AA, van de Ven J, Fransen AF, Dieleman JP, van Runnard Heimel PJ, Oei SG. Risk factors of incomplete Apgar score and umbilical cord blood gas analysis: a retrospective observational study. J Matern Fetal Neonatal Med. 2016;24:1-6.

22. Adebamowo CA, Ezeome ER, Ajuwon AJ, Adekunle OO. Job stress associated with surgical training in Nigeria. Afr J med med Sci. 1998;27(3):233-7.

23. Harvey E. Staff surgeon competence. J Can Chir. 2011;54:4.

24. Kramer M. Sleep loss in resident physicians: the cause of medical errors? Frontiers Neur. 2010;128:1.

25. Dawson D, Zee P. Work hours and reducing fatigue-related risk: good research vs. good policy. JAMA. 2005;294:1104-6.

26. Colten HR, Altevogt BM. Sleep disorders and sleep deprivation: an unmet public health problem. Washington DC: National Academies Press; 2006.

27. Lockley SW, Cronin JW, Evans EE, Cade BE, Lee CJ, Landrigan CP, et al. Effect of reducing interns' weekly work hours on sleep and attention failures. $\mathrm{N}$ Engl J med. 2004;351:1829-37.

28. Howard SK, Rosekind MR, Katz JD, Berry AJ. Fatigue in anesthesia: implications and strategies for patient and provider safety. Anesthesia. 2002a;97:1281-94

29. Parthasarathy S. Sleep and the medical profession. Curr Opin Pulm med. 2011;2005:507-12.

30. Businger A, Guller U, Oertli D. Effect of the 50-hour workweek limitation on training of surgical residents in Switzerland. Arch Surg. 2010;145(6):558-63.

31. Hoque $M$, Hoque $S$. Timing of spontaneous birth and the risk of adverse perinatal outcome. South Afr J Epidemiol Infect. 2010;25:4.

32. Muhimbili National Hospital, Birth Registry. MNH, Dar es Salaam: 2014.

33. Temeke Regional Hospital, Maternity records. POLGRA, Dar es Salaam: 2014. 
34. Amana Regional Hospital, Maternity records. POLGRA, Dar es Salaam: 2014

35. Mwananyamala Regional, Hospital, Maternity records. POLGRA, Dar es Salaam: 2014.

36. Kaur J, Kaur K. Obstetric complications: Primiparity vs. Multiparity Eur J Exper Bio. 2012;2:12.

37. Kidanto H, Mogren I, van Roosmalen J, Thomas A, Massawe S, Nystrom L, et al. Introduction of a qualitative perinatal audit at Muhimbili National Hospital, Dar es Salaam. Tanzania BMC Pregnancy Childbirth. 2009;9:45.

38. Baba S, Goto A, Reich MR. Recent pregnancy trends among early adolescent girls in Japan. J Obstet Gynecol Res. 2013;10:1213-8.

39. Arsenault C, Fournier P, Philibert A, Sissoko K, Coulibaly A, Tourigny C, et al, Emergency obstetric care in Mali: catastrophic spending and its impoverishing effects on households. Bull World Health Organ. 2013;91:207-16.

40. Mbaruku G, van Roosmalen J, Kimondo I, Bilango F, Bergstrom S. Perinatal audit using 3 delay model in western Tanzania. Int J Obstet Gynecol. 2009:106:85-8.

41. Bayou G, Berhan Y. Perinatal mortality and associated risk factors: a case control study. Ethiop J Health Sci. 2012;22(3):153-62.

42. Mgaya AH, Massawe SN, Kidanto HL, Mgaya HN. Grand multiparity: is it still a risk in pregnancy? BMC Pregnancy Childbirth. 2013;13:241.

43. Litorp H, Kidanto H, Nystrom L, Darj E, Essen B. Increasing caesarean section rate among low-risk groups: a panel study classifying deliveries according to Robson at a university hospital in Tanzania. BMC Pregnancy Childbirth. 2013:13:107.

44. Bailey PE. The disappearing art of instrumental delivery: time to reverse the trend. Int J Gynecol Obstet. 2005;91(1):89-96.

45. Thaddeus S, Maine D. Too far to walk: maternal mortality in context. Soc Sci med. 1994;38(8):1091-110.

46. Pembe AB, Chetto P, D'mello B, van Roosmalen J. Maternal mortality at Muhimbili National Hospital in Dar-es-Salaam, Tanzania in the year 2011. BMC Pregnancy Childbirth. 2014;14:320.

47. Comprehensive Community Based Rehabilitation in Tanzania (CCBRT). The next challenges: Strengthening the referral system. Dar es Salaam: CCBRT; 2016. Availableat:http://www.ccbrt.or.tz/programmes/maternal-newbornhealth/. (Accesed 3 Dec 2016).

48. Kabakyenga JK, Ostergren PO, Turyakira E, Mukasa PK, Pettersson KO. Individual and health facility factors and the risk for obstructed labour and its adverse outcomes in south-western Uganda. BMC Pregnancy Childbirth. 2011;11:73.

49. Kidanto HL, Wangwe P, Kilewo CD, Nystrom L, Lindmark G. Improved quality of management of eclampsia patients through criteria based audit at Muhimbili National Hospital, Dar es Salaam, Tanzania. Bridging the quality gap. BMC Pregnancy Childbirth. 2012;12:134

50. Kidanto H, Msemo G, Mmbando D, Rusibamayila N, Ersdal H, Perlman J. Predisposing factors associated with stillbirth in Tanzania. Int J Gynecol Obstet. 2015;130(1):70-73.

51. Mgaya AH, Litorp $H$, Kidanto HL, Nystrom L, Essén B. Criteria-based audit to improve quality care of foetal distress. Standardising obstetric care at a national referral hospital in a low resource setting BMC Pregnancy and Childbirth 2016;16:343.

52. Mgaya AH, Kidanto HL, Nystrom L, Essén B. Improving standards of Care in Obstructed Labour: a criteria-based audit at a referral hospital in a lowresource setting in Tanzania. PLoS One. 2016;11(11):e0166619.

53. DeJonge A, Twisk J, Hutton E. Daytime births are associated with better perinatal outcomes in secondary and tertiary hospitals. Evid Based med. 2011;16(2):59-60

54. Litorp H, Kidanto H, Rööst M, Abeid M, Nystrom L, Darj E, et al. Maternal near-miss and death and their association with caesarean section complications: a cross-sectional study at a university hospital and a regional hospital in Tanzania. BMC Pregnancy Childbirth. 2014;14:244.

55. Ministry of Health and Social Welfare. Availability and utilization of emergency obstetric and neonatal care in Tanzania mainland. Dar es Salaam: MoHSW; 2015.

\section{Submit your next manuscript to BioMed Central and we will help you at every step:}

- We accept pre-submission inquiries

- Our selector tool helps you to find the most relevant journal

- We provide round the clock customer support

- Convenient online submission

- Thorough peer review

- Inclusion in PubMed and all major indexing services

- Maximum visibility for your research

Submit your manuscript at www.biomedcentral.com/submit
Biomed Central 